\title{
Clopidogrel and Gemfibrozil Strongly Inhibit the CYP2C8-Dependent Formation of 3-Hydroxydesloratadine and Increase Desloratadine Exposure In Humans
}

\author{
Matti K. Itkonen, (®Aleksi Tornio, @Mikko Neuvonen, @Pertti J. Neuvonen, @Mikko Niemi, \\ and $\odot$ Janne T. Backman
}

Department of Clinical Pharmacology, University of Helsinki and Helsinki University Hospital, Helsinki, Finland

Received September 26, 2018; accepted January 7, 2019

\begin{abstract}
A recent in vitro study suggested that CYP2C8 is essential in the metabolism of desloratadine, an $\mathrm{H} 1$ receptor antagonist. If the proposed biotransformation mechanism takes place in vivo in humans, desloratadine could serve as a selective CYP2C8 probe substrate in drug-drug interaction studies. Glucuronide metabolites of clopidogrel and gemfibrozil act as time-dependent inhibitors of CYP2C8, but they have not been compared clinically. We conducted a randomized crossover study in $\mathbf{1 1}$ healthy subjects to characterize the involvement of CYP2C8 in desloratadine metabolism and to compare the CYP2C8 inhibitory strength of clopidogrel ( 300 and $75 \mathrm{mg}$ on two following days) with that of gemfibrozil ( $600 \mathrm{mg}$ BID for 5 days). Compared with placebo (control), clopidogrel increased the area under the plasma concentration-time curve $\left(\mathrm{AUC}_{0_{-\infty}}\right)$ and peak plasma concentration $\left(C_{\max }\right)$ of desloratadine to $280 \%\left(P=3 \times 10^{-7}\right)$
\end{abstract}

and $165 \%(P=0.0006)$, respectively. The corresponding increases by gemfibrozil were to $462 \%\left(P=4 \times 10^{-7}\right)$ and $174 \%(P=0.0006)$. Compared with placebo, clopidogrel and gemfibrozil decreased 3-hydroxyloratadine $\mathrm{AUC}_{0-71 \mathrm{~h}}$ to $52 \%\left(P=5 \times 10^{-5}\right)$ and $6 \%(P=$ $\left.2 \times 10^{-8}\right)$, respectively. Moreover, the 3-hydroxydesloratadine: desloratadine $\mathrm{AUC}_{0-71} \mathrm{~h}$ ratios were $21 \%\left(P=7 \times 10^{-10}\right)$ and $1.7 \%$ $\left(P=8 \times 10^{-11}\right)$ of control during the clopidogrel and gemfibrozil phases. Our results confirm that CYP2C8 plays a critical role in the formation of 3-hydroxydesloratadine in humans, making desloratadine a potential CYP2C8 probe substrate. Furthermore, the findings corroborate the previous estimates that clinically relevant doses of clopidogrel cause strong CYP2C8 inhibition, whereas those of gemfibrozil almost completely inactivate the enzyme in humans.

\section{Introduction}

Desloratadine is a potent, nonsedating H1 histamine receptor antagonist indicated for symptomatic relief of urticaria and allergic rhinitis (https://www.accessdata.fda.gov/drugsatfda_docs/label/2014/ 021165s017,021300s014,021312s015,021563s003lbl.pdf; Henz, 2001). It has linear pharmacokinetics in the 5- to 20 -mg dose range, is $82 \%-$ $87 \%$ bound to plasma proteins, and has a terminal half-life $\left(t_{1 / 2}\right)$ of about 21-27 hours (Henz, 2001; Murdoch et al., 2003; Molimard et al., 2004). It is extensively metabolized, and its major metabolite is 3-hydroxydesloratadine, which is further glucuronidated to 3hydroxydesloratadine- $O$-glucuronide (Molimard et al., 2004). A recent in vitro study suggested a central role for cytochrome P450 2C8 (CYP2C8) in the formation of the 3-hydroxy metabolite, involving initial $\mathrm{N}$ glucuronidation of desloratadine followed by CYP2C8-dependent oxidation of the $\mathrm{N}$-glucuronide and subsequent rapid deconjugation (Fig. 1) (Kazmi et al., 2015a). The proposed CYP2C8-selective metabolism and the benign safety profile could make desloratadine a practical

This study was supported by grants from the Academy of Finland [Grant decision 278123, 2014] and by State funding for university-level health research [Hospital District of Helsinki and Uusimaa, Finland].

https://doi.org/10.1124/dmd.118.084665.
CYP2C8 probe substrate in drug-drug interaction (DDI) studies (Prenner et al., 2006).

The acyl- $\beta$-D-glucuronide metabolite of the antiplatelet agent clopidogrel and the 1-O-glucuronide metabolite of the fibric acid derivative gemfibrozil act as mechanism-based inhibitors of CYP2C8 (Ogilvie et al., 2006; Tornio et al., 2014; Backman et al., 2016). Accordingly, in humans, clopidogrel and gemfibrozil have significantly increased the exposure to several CYP2C8 substrates such as cerivastatin, repaglinide, pioglitazone, montelukast, and dasabuvir (Backman et al., 2002, 2016; Niemi et al., 2003; Jaakkola et al., 2005; Karonen et al., 2010; Tornio et al., 2014; Itkonen et al., 2016, 2018, 2019). Recently, both clopidogrel and gemfibrozil were suggested as model CYP2C8 inhibitors for DDI studies in the FDA Draft Guidance for Clinical Drug Interaction Studies (https://www.fda.gov/downloads/drugs/guidances/ucm292362.pdf). The CYP2C8-inhibitory strength of clopidogrel, however, has not been directly compared with that of gemfibrozil in a clinical setting.

Glucuronide metabolites have generally been regarded as relatively stable and physiologically inactive compounds, but owing to the reactivity of acyl glucuronides as well as their ability to act as perpetrators in drug interactions, these presumptions have been challenged by Ogilvie et al. (2006), Regan et al. (2010), Tornio et al. (2014), and Backman et al. (2016). Apart from the ability of CYP2C8 to reactivate glucuronides of gemfibrozil, clopidogrel, and deleobuvir, leading to $\mathrm{CYP} 2 \mathrm{C} 8$ inactivation, several

ABBREVIATIONS: AUC, area under the plasma concentration-time curve; BID, twice daily; $\mathrm{Cl}$, confidence interval; $C_{\max }$, peak plasma concentration; CV, coefficients of variation; DDI, drug-drug interaction; LC-MS/MS, liquid chromatography-tandem mass spectrometry; LLQ, lower limit of quantification; OATP, organic anion-transporting polypeptide; P450, cytochrome P450; QD, every day; $t_{1 / 2}$, terminal half-life; $t_{\text {max }}$, time to $C_{\text {max }}$; UGT, uridine 5'-diphospho-glucuronosyltransferase. 

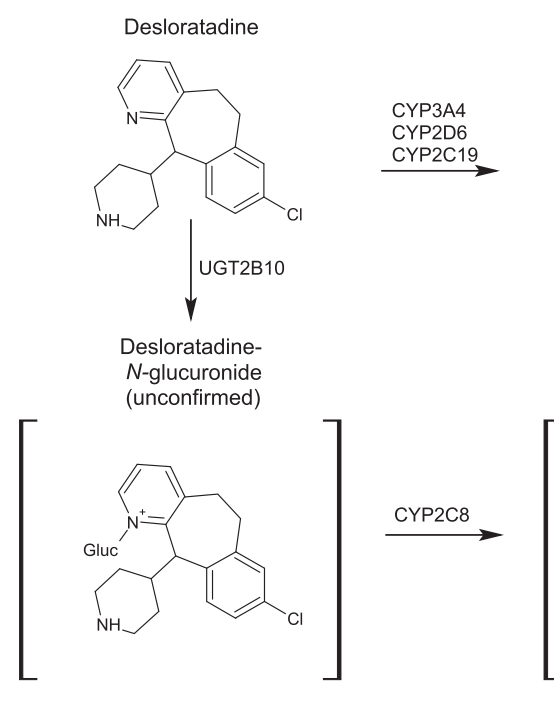

or

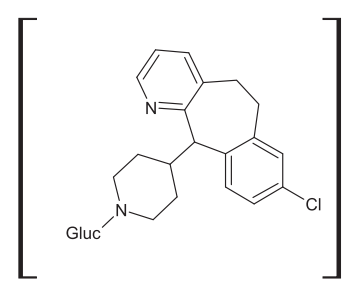

5-hydroxydesloratadine

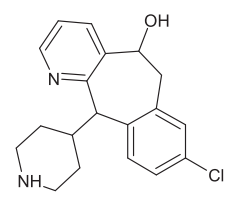

3-hydroxydesloratadine-

$\mathrm{N}$-glucuronide

(unconfirmed)

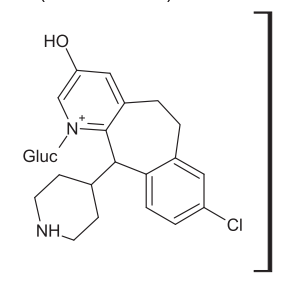

or

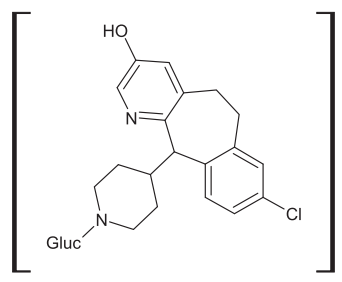

6-hydroxydesloratadine

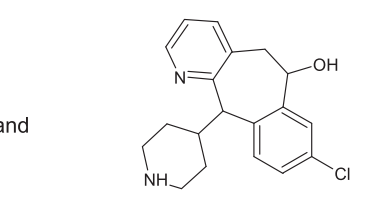

and

3-hydroxydesloratadine

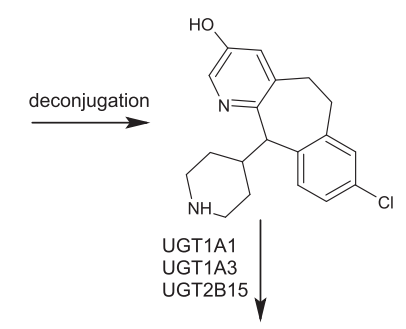

3-hydroxydesloratadine-O-glucuronide

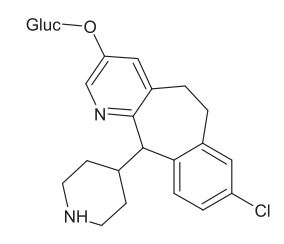

Fig. 1. The proposed biotransformation pathways and the chemical structures of desloratadine and its 5-hydroxy, 6-hydroxy, $\mathrm{N}$-glucuronide, 3-hydroxy, and 3-hydroxy-Oglucuronide metabolites (Kazmi et al., 2015a). glucuronides of xenobiotics and steroid hormones, including those of diclofenac, licofelone, estradiol, and desloratadine, have been shown to undergo CYP2C8-mediated oxidation in vitro (Kumar et al., 2002; Delaforge et al., 2005; Albrecht et al., 2008; Backman et al., 2016). However, research on pharmacological activity and qualities of glucuronides is still scarce, and their potential to act as DDI perpetrators has not been routinely screened during drug development. Moreover, clinical data demonstrating the role of CYP2C8 in the metabolism of glucuronide compounds is lacking.

The primary objectives of the present clinical study were to examine the role of CYP2C8 in desloratadine metabolism and evaluate the applicability of desloratadine as a CYP2C8 probe substrate. Moreover, we aimed to compare head-to-head the CYP2C8 inhibitory effects of the typical clinically used doses of clopidogrel and gemfibrozil in vivo in humans.

\section{Materials and Methods}

Subjects and Study Design. Twelve subjects were recruited for the study, but one of them withdrew from the study after the second phase for personal reasons. Eleven healthy nonsmoking volunteers (six women, five men; age range, 20-29 years; body mass index range, $18.6-27.3 \mathrm{~kg} / \mathrm{m}^{2}$ ) participated in the study after giving written informed consent. Their health was confirmed by medical history, clinical examination, and routine laboratory tests before entering the study. All participants had normal blood platelet counts and hemoglobin values. None of the subjects used oral contraceptives or other continuous medication. The study protocol was approved by the Coordinating Ethics Committee of the Helsinki and Uusimaa Hospital District (record number 296/13/03/00/2015), and the Finnish Medicines Agency Fimea (EudraCT number 2015-000368-32). In a randomized, placebo-controlled, three-phase crossover study, the subjects ingested as pretreatment either gemfibrozil on days 1-5 [600 mg twice daily (BID), at $8 \mathrm{AM}$ and 8 PM; Lopid; Pfizer Manufacturing Deutschland GmbH, Freiburg, Germany], clopidogrel on days 3-5 (300 mg at $8 \mathrm{AM}$ on day 3 followed by $75 \mathrm{mg}$ on days 4-5; Plavix, Sanofi-Aventis, Paris, France), or placebo on days 1-5 (twice daily at 8 AM and 8 PM; placebo tablets, University Pharmacy, Helsinki, Finland). Between the phases, there was a wash-out period of at least 3 weeks. On day 3, $5 \mathrm{mg}$ of desloratadine (Aerius 5-mg tablet; Merck Sharp \& Dohme Ltd, Hoddeson, United Kingdom) was administered at $9 \mathrm{AM}$ with $150 \mathrm{ml}$ water. On the days of desloratadine ingestion, the volunteers had fasted overnight, and a standard warm meal was served 3 hours and snacks 7 and 10 hours after the administration of desloratadine. The use of grapefruit products was not allowed for 1 week before and during the study, and the use of other drugs from 1 week before to 1 week after the study. The subjects experienced no significant or unexpected adverse effects.

Sampling. Timed venous blood samples (4 or $9 \mathrm{ml})$ were drawn before the administration of pretreatment on the morning of day 3 , and 5 minutes before and $0.5,1,2,3,4,5,7,9,11,23,47$, and 71 hours after the administration of desloratadine. The blood samples were collected into tubes containing EDTA, which were placed on ice immediately after sampling. Plasma was separated within 30 minutes and stored at $-70^{\circ} \mathrm{C}$ until analysis. The samples for the determination of clopidogrel and its metabolites were treated with 2-bromo-3'methoxyacetophenone within 30 seconds of blood sample collection in whole blood EDTA samples, to derivatize the active metabolite of clopidogrel, as previously described (Holmberg et al., 2014).

Determination of Plasma Desloratadine and Its Metabolites. Prior to quantification by liquid chromatography-tandem mass spectrometry (LC-MS/MS), the plasma samples were purified by solid phase extraction using Strata-X Polymeric Reversed Phase, 96-Well Plate (10 mg/well; Phenomenex, Torrance, CA). In brief, the samples $(120 \mu \mathrm{l})$ were mixed with $100 \mu \mathrm{l}$ of internal standard solution containing desloratadine-d5 and 3-hydroxydesloratadine- $\mathrm{d} 4(5 \mathrm{ng} / \mathrm{ml})$ in $50 \mathrm{mM}$ ammonium acetate ( $\mathrm{pH} 4.7)$, and drawn through the preconditioned extraction plate. The wells were then washed with $10 \%$ methanol and the analytes were eluted with methanol containing $1 \%$ formic acid. Finally, the sample extracts were dried using a centrifugal evaporator (GeneVac; Thermo Fisher Scientific, Waltham, MA) and reconstituted in $100 \mu 1$ of mobile phase starting composition. The analytes were separated on a Kinetex C18 XB column (2.6- $\mu \mathrm{m}$ particle size, $2.1 \times 100$-mm internal diameter; Phenomenex) using a Nexera $\times 2$ ultra-highperformance liquid chromatography system (Shimadzu, Kyoto, Japan). The mobile phase consisted of $0.02 \%$ formic acid in $5 \mathrm{mM}$ ammonium acetate (mobile 
phase A) and acetonitrile (mobile phase B), and a solvent gradient was adopted as follows for the total run time of 11 minutes: 3 minutes at $20 \% \mathrm{~B}$; a linear increase from $20 \% \mathrm{~B}$ to $63 \%$ B over 3 minutes; 1 minute at $90 \% \mathrm{~B} ; 4$ minutes equilibration at $20 \% \mathrm{~B}$. The flow rate and the column temperature were maintained at $300 \mu \mathrm{l} / \mathrm{min}$ and $30^{\circ} \mathrm{C}$, and an aliquot of $2 \mu \mathrm{l}$ was injected into the system. A Sciex 5500 Qtrap tandem mass spectrometer (Sciex, Toronto, Ontario, Canada) interfaced with an electrospray ion source was used for the mass spectrometric detection. The mass spectrometer was operated in the positivepolarity multiple-reaction mode and the Q1 and Q3 quadrupoles were set at unit mass resolution. The mass transitions $(\mathrm{m} / \mathrm{z}) 311$ to 259,327 to 275 , and 503 to 327 were selected for desloratadine, 3-hydroxydesloratadine, and 3-hydroxydesloratadine $\mathrm{N}$-glucuronide, respectively. The lower limit of quantification (LLQ) for desloratadine and 3-hydroxydesloratadine were 0.05 and $0.025 \mathrm{ng} / \mathrm{ml}$, respectively. A signal-to-noise ratio of 3:1 was used as a limit of detection for 3-hydroxydesloratadine $N$-glucuronide, and the quantities were given in arbitrary units (units per milliliter) relative to the ratio of the peak heights of the 3-hydroxydesloratadine $\mathrm{N}$-glucuronide to the internal standard (3-hydroxydesloratadine-d4). The day-to-day coefficients of variation $(\mathrm{CV})$ were $6.0 \%(0.2 \mathrm{ng} / \mathrm{ml}), 2.6 \%(2.0 \mathrm{ng} / \mathrm{ml})$, and $4.6 \%(20 \mathrm{ng} / \mathrm{ml})$ for desloratadine, and $4.2 \%(0.1 \mathrm{ng} / \mathrm{ml}), 2.1 \%(1.0 \mathrm{ng} / \mathrm{ml})$, and $3.5 \%(10 \mathrm{ng} / \mathrm{ml})$ for 3-hydroxydesloratadine.

Determination of Plasma Gemfibozil and Gemfibrozil-1- $O$-Glucuronide. The plasma gemfibrozil and gemfibrozil-1-O-glucuronide were purified using a simple protein precipitation with acetonitrile (1:3) containing the corresponding deuterium-labeled internal standards, gemfibrozil-d6, and gemfibrozil-1-Oglucuronide-d6 $(0.5 \mu \mathrm{g} / \mathrm{ml})$. The plasma extract was then further diluted with water and introduced to the Sciex 5500 Qtrap LC-MS/MS System. The chromatographic separation of the analytes was carried out on a Kinetex C18 column $(75 \times 2.1-\mathrm{mm}$ internal diameter, $2.6-\mu \mathrm{m}$ particle size; Phenomenex $)$ using $2 \mathrm{mM}$ ammonium acetate ( $\mathrm{pH} 4$ ) and acetonitrile (mobile phase $\mathrm{B}$ ). The following gradient conditions were applied: 1 minute at $20 \% \mathrm{~B}$ on hold, then a linear increase from $20 \% \mathrm{~B}$ to $90 \% \mathrm{~B}$ over 4 minutes followed by a re-equilibration step back to the initial conditions ( $20 \%$ B). The characteristic negative multiple reaction mode ion transitions, $\mathrm{m} / \mathrm{z} 249$ to 121 and $\mathrm{m} / \mathrm{z} 425$ to 121 , were used for the quantification of gemfibrozil and gemfibrozil-1-O-glucuronide. The lower LLQ for both analytes was $0.05 \mu \mathrm{g} / \mathrm{ml}$ and the day-to-day coefficients of variation were below $10 \%$ at relevant concentrations.

Determination of Plasma Clopidogrel and Its Metabolites. The plasma clopidogrel and its metabolites were measured using a Sciex 5500 Qtrap LC-MS/MS system as previously described (Holmberg et al., 2014; Tornio et al., 2014; Itkonen et al., 2015). The LLQs were $0.05 \mathrm{ng} / \mathrm{ml}$ for clopidogrel and clopidogrel active cis-5-thiol metabolite, $20 \mathrm{ng} / \mathrm{ml}$ for clopidogrel carboxylic acid, and $25 \mathrm{ng} / \mathrm{ml}$ for clopidogrel acyl- $\beta$-D-glucuronide. The day-to-day precision values for all compounds were below $15 \%$ (expressed as $\mathrm{CV} \%$ ) and the accuracy was within $\pm 15 \%$, except for LLQ, for which both precision and accuracy were within $\pm 20 \%$.

Pharmacokinetics. The peak plasma concentration $\left(C_{\max }\right)$, time to $C_{\max }\left(t_{\max }\right)$, area under the plasma concentration-time curve from time $0-71$ hours $\left(\mathrm{AUC}_{0-71 \mathrm{~h}}\right)$, $\mathrm{AUC}_{0-\infty}$ (when appropriate), and $t_{1 / 2}$ were calculated for desloratadine and its metabolites by standard noncompartmental methods using Phoenix WinNonlin, version 6.4 (Certara, Princeton, NJ). In the gemfibrozil phase, the concentrations of 3-hydroxydesloratadine and desloratadine 3-hydroxy-O-glucuronide were under the LLQ at several time points after the administration of desloratadine. To calculate the $\mathrm{AUC}_{0-71 \mathrm{~h}}$, the aforementioned concentration values lower than LLQ were replaced with values equal to half of the LLQ. For gemfibrozil, clopidogrel, and their metabolites, $C_{\max }, t_{\max }, t_{1 / 2}$, and $\mathrm{AUC}_{0-12 \mathrm{~h}}$ were calculated.

Genotyping. Buffy coats were prepared from $9 \mathrm{ml}$ of whole-blood EDTA samples after plasma separation. Genomic DNA was extracted from the buffy coats using the Maxwell 16 LEV Blood DNA Kit on a Maxwell 16 Research automated nucleic acid extraction system (Promega, Madison, WI). The participants were genotyped for the CYP2C8*2 (rs11572103), *3 (rs10509681 and rs11572080), and $* 4($ rs1058930) alleles with commercially available or custom TaqMan assays with OpenArray technology on a QuantStudio 12K Flex real-time PCR system (Life Technologies/Thermo Fisher Scientific, Carlsbad, CA).

Two of the subjects had the $C Y P 2 C 8 * 1 / * 3$ genotype, and two had the CYP $2 C 8 * 1 / * 4$ genotype, whereas the others had the CYP $2 C 8 * 1 / * 1$ genotype. There were no apparent genotype-dependent differences in the pharmacokinetics of desloratadine or its metabolites (data not shown). Owing to the small sample size and lack of subjects with desloratadine "poor metabolizer" phenotype, UGT2B10 was not included in the genotyping panel.

Drug-Drug Interaction Predictions. Inhibition of CYP2C8 by clopidogrel acyl- $\beta$-D-glucuronide and gemfibrozil 1-O-glucuronide was predicted using mechanism-based in vitro inhibition values from the literature with a mechanistic static model according to following equation:

$$
\text { Activity remaining }=\frac{k_{\text {deg }}}{k_{\text {deg }}+\frac{k_{\text {inact }} \times I}{K_{I}+I}}
$$

where $k_{\text {deg }}$ is the rate constant of hepatic P450 degradation in the absence of the inhibitor, $k_{\text {inact }}$ is the maximum inactivation rate, $I$ is the unbound inhibitor concentration at the enzyme site, and $K_{I}$ is the inhibitor concentration needed to cause half of $k_{\text {inact }}$. A half-life of 22 hours for CYP2C8 was used, corresponding to $k_{\text {deg }}$ of 0.000525 (Backman et al., 2009). The $k_{\text {inact }}$ values were $2.821 / \mathrm{min}$ and $0.211 / \mathrm{min}$, and $K_{I}$ values were $9.9 \mu \mathrm{M}$ and $20 \mu \mathrm{M}$ for clopidogrel acyl- $\beta$-Dglucuronide and gemfibrozil 1-O-glucuronide, respectively (Ogilvie et al., 2006; Tornio et al., 2014).

Statistical Analysis. On the basis of our previous drug interaction studies, twelve subjects were estimated to be adequate to detect a $30 \%$ change in the AUC of the victim drug and its main metabolite between the placebo (control) and clopidogrel and gemfibrozil phases, with a power of at least $80 \%$ ( $\alpha$ level $5 \%$ ). The results are expressed as geometric means and geometric mean ratios with geometric CV or $90 \%$ confidence intervals (CIs) unless stated otherwise. Logarithmic transformation was used for pharmacokinetic variables, except $t_{\text {max }}$, before statistical analysis. The pharmacokinetic variables were compared by repeated-measures analysis of variance with treatment phase as a withinsubjects factor, followed by pairwise comparisons with Bonferroni-corrected analysis of variance. The $t_{\max }$ data were compared using the Wilcoxon signed rank test. Correlations between the fold-change in desloratadine AUC and the 3-hydroxydesloratadine:desloratadine $\mathrm{AUC}_{0-71 \mathrm{~h}}$ ratio between clopidogrel and gemfibrozil phases were quantified as Pearson's correlation coefficients. $P$-values below 0.05 were considered statistically significant. Statistical analyses were performed using SPSS Statistics for Windows version 22.0 (IBM Corporation, Armonk, NY).

\section{Results}

Effect of Clopidogrel on Parent Desloratadine. Compared with placebo (control), clopidogrel increased desloratadine $\mathrm{AUC}_{0-\infty}$ to $280 \%$ $\left(P=3 \times 10^{-7} ; 90 \%\right.$ CI $\left.232 \%-338 \%\right)$. In addition, the $C_{\max }$ of desloratadine was increased to $165 \%(P=0.0006$; $90 \%$ CI $133 \%-204 \%)$ and its $t_{1 / 2}$ prolonged from 17 to 26 hours (ratio to control $150 \% ; P=$ 0.0003 ; $90 \%$ CI 130\%-180\%) by clopidogrel (Fig. 2; Table 1).

Effect of Clopidogrel on 3-Hydroxydesloratadine. Clopidogrel decreased the 3-hydroxydesloratadine $\mathrm{AUC}_{0-\infty}$ to $74 \%\left(P=5 \times 10^{-5}\right.$; $90 \%$ CI $69 \%-80 \%$ ) of control. Moreover, in the clopidogrel phase, the 3-hydroxydesloratadine:desloratadine $\mathrm{AUC}_{0-71 \mathrm{~h}}$ ratio was $21 \%(P=$ $7 \times 10^{-10} ; 90 \%$ CI $\left.18 \%-24 \%\right)$ of that during the control phase. Compared with placebo, clopidogrel decreased 3-hydroxydesloratadine $C_{\max }$ to $30 \%\left(P=1 \times 10^{-7} ; 90 \%\right.$ CI $\left.25 \%-37 \%\right)$, and prolonged the $t_{1 / 2}$ from 25 to 51 hours (ratio to control $200 \% ; P=2 \times 10^{-5} ; 90 \% \mathrm{CI}$ $170 \%-240 \%)$.

Effect of Clopidogrel on 3-Hydroxydesloratadine- $\boldsymbol{O}$-Glucuronide. During the clopidogrel phase, the $\mathrm{AUC}_{0-\infty}$ of 3-hydroxydesloratadine$O$-glucuronide was $71 \%(P=0.0008 ; 90 \% \mathrm{CI} 62 \%-81 \%)$ of that in the placebo phase. Furthermore, the $C_{\max }$ of 3-hydroxydesloratadine- $O$ glucuronide was decreased to $37 \%\left(P=3 \times 10^{-7} ; 90 \%\right.$ CI $\left.31 \%-45 \%\right)$ and its $t_{1 / 2}$ prolonged from 19 to 35 hours $\left(P=2 \times 10^{-5} ; 90 \%\right.$ CI $163 \%-$ $218 \%$ ) by clopidogrel, compared with those in the control phase.

Effect of Gemfibrozil on Parent Desloratadine. Compared with placebo (control), gemfibrozil increased desloratadine $\mathrm{AUC}_{0-\infty}$ to $462 \%$ $\left(P=4 \times 10^{-7} ; 90 \%\right.$ CI $\left.346 \%-616 \%\right)$. The $C_{\max }$ of desloratadine was increased to $174 \%(P=0.0006 ; 90 \%$ CI $137 \%-221 \%)$ of control and $t_{1 / 2}$ prolonged from 17 to 39 hours (ratio to control $220 \% ; P=3 \times 10^{-8}$; $90 \%$ CI 200\%-250\%) by gemfibrozil (Fig. 2; Table 1). 
A
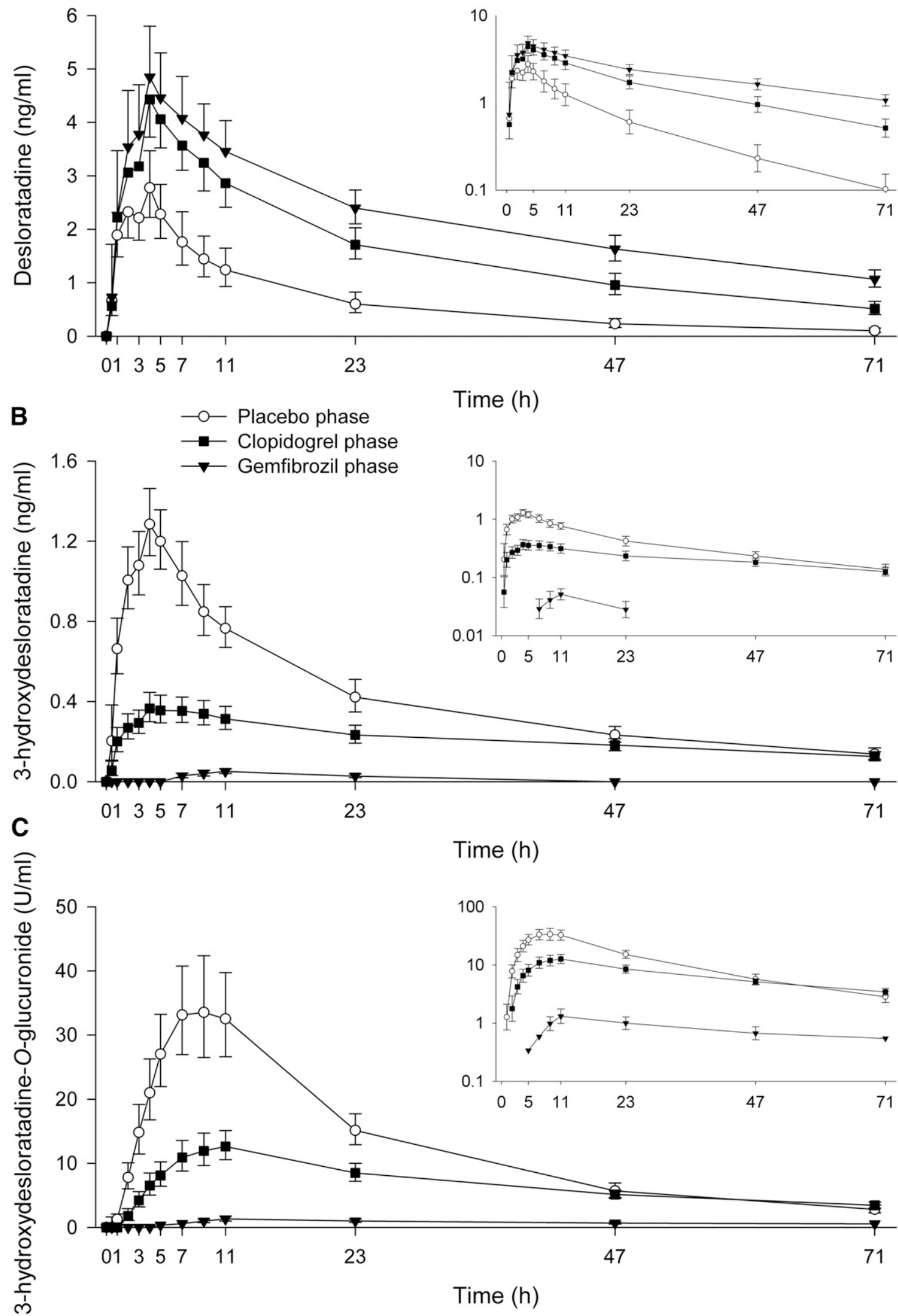

Fig. 2. The effect of clopidogrel (300 $\mathrm{mg}$ on day 3, followed by $75 \mathrm{mg}$ on days 4 and 5) and gemfibrozil (600 mg twice daily on days 1-5) on the plasma concentrations of desloratadine (A), and its 3-hydroxy (B), and 3-hydroxy-O-glucuronide (C) metabolites. On day 3, desloratadine $5 \mathrm{mg}$ was administered to 11 healthy volunteers 1 hour after the morning dose of each pretreatment. Data are presented as geometric means with $90 \%$ confidence intervals. For clarity, some error bars have been omitted. Insets depict the same data on semilogarithmic scale. 
TABLE 1

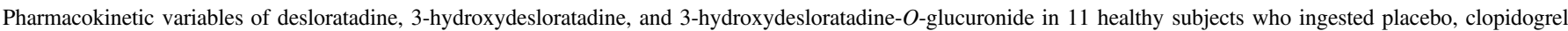

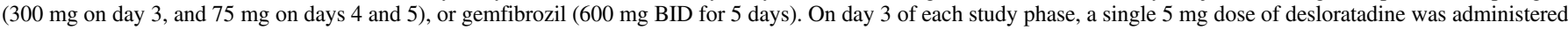
1 hour after pretreatment.

Data are given as geometric mean with geometric coefficient of variation (in brackets), except for $\mathrm{t}_{\max }$, which is given as median with range. The geometric mean ratios between the clopidogrel and placebo phases and gemfibrozil and clopidogrel phases are given with 90\% CI (in brackets).

\begin{tabular}{|c|c|c|c|c|c|c|}
\hline Variable & $\begin{array}{l}\text { Placebo } \\
\text { Phase }\end{array}$ & $\begin{array}{l}\text { Clopidogrel } \\
\text { Phase }\end{array}$ & $\begin{array}{l}\text { Clopidogrel to } \\
\text { Placebo Phase Ratio } \\
\text { (90\% CI) }\end{array}$ & $\begin{array}{l}\text { Gemfibrozil } \\
\text { Phase }\end{array}$ & $\begin{array}{l}\text { Gemfibrozil to } \\
\text { Placebo Phase Ratio } \\
(90 \% \mathrm{CI})\end{array}$ & $\begin{array}{l}\text { Gemfibrozil to Clopidogrel } \\
\text { Phase Ratio (90\% CI) }\end{array}$ \\
\hline \multicolumn{7}{|l|}{ Desloratadine } \\
\hline$C_{\max }(\mathrm{ng} / \mathrm{ml})$ & $2.83(43)$ & $4.65(28)$ & $1.65(1.33-2.04)^{* * *}$ & $4.93(34)$ & $1.74(1.37-2.21)^{* * *}$ & $1.06(0.90-1.24) ; P>0.9$ \\
\hline$t_{\max }(\mathrm{h})$ & $4(1.0-7.0)$ & $4.0(4.0-7.0)$ & $P=0.4$ & $4.0(3.0-7.0)$ & $P>0.9$ & $P>0.9$ \\
\hline$t_{1 / 2}(\mathrm{~h})$ & $17(19)$ & $26(18)$ & $1.5(1.3-1.8)^{* * *}$ & 39 (19) & $2.2(2.0-2.5)^{* * *}$ & $1.5(1.2-1.8) \dagger \dagger \dagger$ \\
\hline $\operatorname{AUC}_{0-71 \mathrm{~h}}(\mathrm{ng} \times \mathrm{h} / \mathrm{ml})$ & $44.3(55)$ & $111(32)$ & $2.51(2.05-3.07) * * *$ & $156(27)$ & $3.51(2.67-4.63)^{* * *}$ & $1.40(1.24-1.59) \dagger \dagger \dagger$ \\
\hline $\operatorname{AUC}_{0-\infty}(\mathrm{ng} \times \mathrm{h} / \mathrm{ml})$ & $46.8(56)$ & $131(36)$ & $2.80(2.32-3.38)^{* * * *}$ & $216(28)$ & $4.62(3.46-6.16)^{* * *}$ & $1.65(1.42-1.91) \dagger \dagger \dagger$ \\
\hline \multicolumn{7}{|l|}{ 3-Hydroxydesloratadine } \\
\hline$C_{\max }(\mathrm{ng} / \mathrm{ml})$ & $1.29(24)$ & $0.388(34)$ & $0.30(0.25-0.37)^{* * *}$ & $0.05(42)$ & $0.04(0.03-0.05)^{* * *}$ & $0.13(0.10-0.17) \dagger \dagger \dagger$ \\
\hline$t_{\max }(\mathrm{h})$ & $4.0(4.0-7.0)$ & $4.0(4.0-11.0)$ & $P=0.2$ & $11.0(7.0-11.0)$ & $P=0.009$ & $P=0.021$ \\
\hline$t_{1 / 2}(\mathrm{~h})$ & $25(13)$ & 51 & $2.0(1.7-2.4)^{* * * *}$ & N/A & - & - \\
\hline $\mathrm{AUC}_{0-71 \mathrm{~h}}(\mathrm{ng} \times \mathrm{h} / \mathrm{ml})$ & $29.5(27)$ & $15.4(30)$ & $0.52(0.44-0.62)^{* * *}$ & $1.81(54)$ & $0.06(0.04-0.09)^{* * *}$ & $0.12(0.09-0.16) \dagger \dagger \dagger$ \\
\hline $\mathrm{AUC}_{0-\infty}(\mathrm{ng} \times \mathrm{h} / \mathrm{ml})$ & $34.3(28)$ & $25.5(30)$ & $0.74(0.69-0.80)^{* * *}$ & N/A & - & - \\
\hline $\begin{array}{l}\text { 3-Hydroxydesloratadine: } \\
\text { desloratadine }\end{array}$ & $0.666(53)$ & $0.139(47)$ & $0.21(0.18-0.24)^{* * *}$ & $0.012(70)$ & $0.017(0.013-0.024)^{* * *}$ & $0.08(0.07-0.11) \dagger \dagger \dagger$ \\
\hline \multicolumn{7}{|l|}{$\mathrm{AUC}_{0-71 \mathrm{~h}}$ ratio } \\
\hline \multicolumn{7}{|c|}{ 3-Hydroxydesloratadine- $O$-glucuronide } \\
\hline$C_{\max }(\mathrm{ng} / \mathrm{ml})$ & $35.0(40)$ & $13.0(34)$ & $0.37(0.31-0.45)^{* * *}$ & $1.32(54)$ & $0.04(0.02-0.06)^{* * *}$ & $0.10(0.07-0.15) \dagger \dagger \dagger$ \\
\hline$t_{\max }(\mathrm{h})$ & $9.0(7.0-11.0)$ & $9.0(7.0-11)$ & $P=0.9$ & $11.0(11.0-23.0)$ & $P=0.03$ & $P=0.048$ \\
\hline$t_{1 / 2}(\mathrm{~h})$ & $19(18)$ & $35(36)$ & $1.9(1.6-2.2)^{* * * *}$ & N/A & - & - \\
\hline $\mathrm{AUC}_{0-71 \mathrm{~h}}(\mathrm{ng} \times \mathrm{h} / \mathrm{ml})$ & $863(32)$ & $475(25)$ & $0.55(0.46-0.65)^{* * *}$ & $54.5(47)$ & $0.06(0.04-0.10)^{* * *}$ & $0.11(0.09-0.15 \dagger \dagger \dagger$ \\
\hline $\mathrm{AUC}_{0-\infty}(\mathrm{ng} \times \mathrm{h} / \mathrm{ml})$ & $940(32)$ & $666(18)$ & $0.71(0.62-0.81)^{* * *}$ & N/A & - & - \\
\hline
\end{tabular}

N/A, not applicable.

$* * * P<0.001$ vs. placebo phase, $\dagger+\uparrow P<0.001$ vs. clopidogrel phase.

Effect of Gemfibrozil on 3-Hydroxydesloratadine. During the gemfibrozil phase, the concentrations of 3-hydroxydesloratadine were very low, and the 3-hydroxydesloratadine $\mathrm{AUC}_{0-71 \mathrm{~h}}$ and 3-hydroxydesloratadine:desloratadine $\mathrm{AUC}_{0-71 \mathrm{~h}}$ ratios were $6 \%(P=$ $\left.2 \times 10^{-8} ; 90 \% \mathrm{CI} 4 \%-9 \%\right)$ and $1.7 \%\left(P=8 \times 10^{-11} ; 90 \%\right.$ CI $1.3 \%-$ $2.4 \%$ ) of control, respectively. Gemfibrozil decreased the $C_{\max }$ of 3-hydroxydesloratadine to $4 \%$ of control $\left(P=8 \times 10^{-10} ; 90 \%\right.$ CI $3 \%-5 \%)$. Owing to the extremely low 3-hydroxydesloratadine concentrations, its $t_{1 / 2}$ could not be reliably determined in most of the subjects in the gemfibrozil phase.

Effect of Gemfibrozil on 3-Hydroxydesloratadine-O-Glucuronide. In the gemfibrozil phase, the $\mathrm{AUC}_{0-71 \mathrm{~h}}$ of 3-hydroxydesloratadine$O$-glucuronide was $6 \%\left(P=7 \times 10^{-8} ; 90 \% \mathrm{CI} 4 \%-10 \%\right)$ and its $C_{\max }$ was $4 \%\left(P=3 \times 10^{-8} ; 90 \% \mathrm{CI} 2 \%-6 \%\right)$ of that in the placebo phase. In addition, the $t_{\max }$ of 3-hydroxydesloratadine- $O$-glucuronide was prolonged from 9.0 to 11.0 hours $(P=0.03)$. As with 3-hydroxydesloratadine, the plasma concentrations of 3-hydroxydesloratadine- $O$-glucuronide were too low for accurate calculation of its $t_{1 / 2}$ during the gemfibrozil phase.

Head-to-Head Comparison of the Effects of Clopidogrel and Gemfibrozil. In general, gemfibrozil's effect on desloratadine pharmacokinetics was stronger than clopidogrel's (Fig. 2). By gemfibrozil, desloratadine $\mathrm{AUC}_{0-\infty}$ was $165 \%\left(P=2 \times 10^{-5} ; 90 \%\right.$ CI $\left.142 \%-191 \%\right)$ of that by clopidogrel. Moreover, 3-hydroxydesloratadine $\mathrm{AUC}_{0-71 \mathrm{~h}}$ was $12 \%\left(P=1 \times 10^{-8} ; 90 \% \mathrm{CI} 9 \%-16 \%\right)$ and the 3-hydroxydesloratadine: desloratadine $\mathrm{AUC}_{0-71 \mathrm{~h}}$ ratio was $8 \%\left(P=7 \times 10^{-10} ; 90 \% \mathrm{CI} 7 \%-11 \%\right)$, compared with those in the clopidogrel phase. Additionally, in the gemfibrozil phase, the $\mathrm{AUC}_{0-71 \mathrm{~h}}$ of 3-hydroxydesloratadine- $O$ glucuronide was $11 \%\left(P=1 \times 10^{-8} ; 90 \%\right.$ CI $\left.9 \%-15 \%\right)$ of that in the clopidogrel phase. There was a significant (Pearson two-tailed, $P=0.002 ; R^{2}=0.80$ ) correlation between the fold-change in desloratadine $\mathrm{AUC}_{0-\infty}$ caused by clopidogrel and that by gemfibrozil (Fig. 2C).

Pharmacokinetic Variables of Clopidogrel and Gemfibrozil. The $C_{\max }$ of clopidogrel and gemfibrozil, as well as their metabolites, were reached 1-3 hours after their ingestion (Table 2), i.e., around or soon after the time of desloratadine administration. There were 50- and 20-fold interindividual variations in parent clopidogrel $C_{\max }$ and $\mathrm{AUC}_{0-12 \mathrm{~h}}$, respectively. In addition, a 3- to 4-fold variation was observed in those of the active $c i s$-5-thiol, carboxylic acid, and acyl- $\beta$-D-glucuronide metabolites of clopidogrel. The variation in the pharmacokinetic variables of gemfibrozil and its $1-O$-glucuronide metabolite was smaller, only up to 2-fold. Consistent with previous DDI studies between clopidogrel or gemfibrozil and CYP2C8 substrates (Backman et al., 2002; Jaakkola et al., 2005; Tornio et al., 2014; Itkonen et al., 2016, 2018, 2019), no significant correlations were observed between the plasma concentrations of clopidogrel acyl- $\beta$-D-glucuronide or gemfibrozil 1- $O$ glucuronide and changes in desloratadine pharmacokinetics.

\section{Discussion}

Recently, CYP2C8 was suggested to have an essential role in the biotransformation of desloratadine to its major metabolite, 3hydroxydesloratadine (Kazmi et al., 2015a). Clopidogrel and gemfibrozil are both clinically relevant $\mathrm{CYP} 2 \mathrm{C} 8$ inhibitors, but previously their CYP2C8 inhibition potency had not been compared with each other in humans. In addition, selective, sensitive, and safe CYP2C8 probe substrates are required for DDI studies. For example, repaglinide, the CYP2C8 probe drug recommended by FDA (https://www.fda.gov/ downloads/drugs/guidances/ucm292362.pdf), has also other disposition mechanisms, e.g., organic anion-transporting polypeptide 1B1 (OATP1B1)-mediated active hepatic uptake and metabolism by CYP3A4 (Tornio et al., 2012), which can complicate data interpretation. For these reasons, we conducted a clinical study in healthy volunteers to investigate the role of CYP2C8 in desloratadine metabolism, and to compare the CYP2C8 inhibitory properties of clopidogrel and gemfibrozil. Overall, both clopidogrel and gemfibrozil increased the exposure to desloratadine and radically reduced the concentrations of 3-hydroxydesloratadine. 


\section{TABLE 2}

Pharmacokinetic variables of clopidogrel, clopidogrel active cis-5-thiol metabolite, clopidogrel carboxylic acid, clopidogrel acyl- $\beta$-D-glucuronide, gemfibrozil, and gemfibrozil 1-O-glucuronide in 11 healthy volunteers after clopidogrel $300 \mathrm{mg}$ or gemfibrozil $600 \mathrm{mg}$ (fifth dose of twice daily dosing) ingested 1 hour before desloratadine $5 \mathrm{mg}$.

Data are given as median with range.

\begin{tabular}{|c|c|}
\hline Variable & Clopidogrel or Gemfibrozil Phase \\
\hline \multicolumn{2}{|l|}{ Clopidogrel } \\
\hline$C_{\max }(\mathrm{ng} / \mathrm{ml})$ & $2.88(0.48-23.2)$ \\
\hline$t_{\max }(\mathrm{h})$ & $1.5(0.92-2.0)$ \\
\hline$t_{1 / 2}(\mathrm{~h})$ & $3.4(2.6-10)$ \\
\hline $\mathrm{AUC}_{0-12 \mathrm{~h}}(\mathrm{ng} \times \mathrm{h} / \mathrm{ml})$ & $11.7(2.22-40.0)$ \\
\hline \multicolumn{2}{|l|}{ Clopidogrel active metabolite } \\
\hline$C_{\max }(\mathrm{ng} / \mathrm{ml})$ & $23.2(11.0-41.2)$ \\
\hline$t_{\max }(\mathrm{h})$ & $0.92(0.92-1.5)$ \\
\hline$t_{1 / 2}(\mathrm{~h})$ & $1.8(1.3-3.9)$ \\
\hline $\mathrm{AUC}_{0-12 \mathrm{~h}}(\mathrm{ng} \times \mathrm{h} / \mathrm{ml})$ & $34.6(16.3-66.0)$ \\
\hline \multicolumn{2}{|l|}{ Clopidogrel carboxylic acid } \\
\hline$C_{\max }(\mathrm{ng} / \mathrm{ml})$ & $9850(7020-15,800)$ \\
\hline$t_{\max }(\mathrm{h})$ & $1.5(0.92-1.5)$ \\
\hline$t_{1 / 2}(\mathrm{~h})$ & $4.2(3.1-8.0)$ \\
\hline $\mathrm{AUC}_{0-12 \mathrm{~h}}(\mathrm{ng} \times \mathrm{h} / \mathrm{ml})$ & $35,400(38,900-92,100)$ \\
\hline \multicolumn{2}{|c|}{ Clopidogrel acyl- $\beta$-D-glucuronide } \\
\hline$C_{\max }(\mathrm{ng} / \mathrm{ml})$ & $3980(1750-7390)$ \\
\hline$t_{\max }(\mathrm{h})$ & $2.0(1.5-3.0)$ \\
\hline$t_{1 / 2}(\mathrm{~h})$ & $3.3(2.7-4.0)$ \\
\hline $\operatorname{AUC}_{0-12 \mathrm{~h}}(\mathrm{ng} \times \mathrm{h} / \mathrm{ml})$ & $14,400(10,900-35,800)$ \\
\hline \multicolumn{2}{|l|}{ Gemfibrozil } \\
\hline$C_{\max }(\mu \mathrm{g} / \mathrm{ml})$ & $18.1(14.3-29.1)$ \\
\hline$t_{\max }(\mathrm{h})$ & $2.0(1.5-4.0)$ \\
\hline$t_{1 / 2}(\mathrm{~h})$ & $2.3(1.7-2.7)$ \\
\hline $\mathrm{AUC}_{0-12 \mathrm{~h}}(\mu \mathrm{g} \times \mathrm{h} / \mathrm{ml})$ & $75.7(56.5-130)$ \\
\hline \multicolumn{2}{|l|}{ Gemfibrozil 1-O-glucuronide } \\
\hline$C_{\max }(\mu \mathrm{g} / \mathrm{ml})$ & $14.5(10.2-20.3)$ \\
\hline$t_{\max }(\mathrm{h})$ & $3.0(1.5-6.0)$ \\
\hline$t_{1 / 2}(\mathrm{~h})$ & $2.5(1.7-3.4)$ \\
\hline $\operatorname{AUC}_{0-12 \mathrm{~h}}(\mu \mathrm{g} \times \mathrm{h} / \mathrm{ml})$ & $80.0(46.2-147)$ \\
\hline
\end{tabular}

On the basis of in vitro results, Kazmi et al. (2015a) suggested an unusual metabolic pathway, by which three distinct consecutive metabolic steps are required for the formation of 3-hydroxydesloratadine (Fig. 1). First, uridine 5' -diphospho-glucuronosyltransferase (UGT) 2B10 metabolizes desloratadine to its $\mathrm{N}$-glucuronide. Subsequently, the $\mathrm{N}$-glucuronide undergoes rapid oxidation to 3-hydroxydesloratadine- $N$-glucuronide very selectively by CYP2C8 (Kazmi et al., 2015a). Finally, the glucuronide moiety is deconjugated, most probably spontaneously, during or very shortly after the CYP2C8-mediated 3-hydroxylation (Kazmi et al., 2015a). The resulting 3-hydroxydesloratadine is further conjugated to $O$ glucuronide by UGT1A1, UGT1A3, and UGT2B15 (Ghosal et al., 2004). The investigators were unable to detect desloratadine- $N$-glucuronide, most probably owing to its instability and rapid CYP2C8-mediated oxidation (Kazmi et al., 2015a). Although desloratadine- $N$-glucuronide was undetectable in the experiments, desloratadine was not 3-hydroxylated by CYP2C8 unless coincubated with UGT2B10, and thus the proposed pathway seems convincing (Kazmi et al., 2015a). Of note, desloratadine is also biotransformed to 5-hydroxy and 6-hydroxy metabolites by several P450 enzymes, namely CYP3A4, CYP2D6, and CYP2C19, in vitro (Barecki et al., 2001; McClellan and Jarvis, 2001; Kazmi et al., 2015b). However, these are only minor elimination pathways, and inhibition of these enzymes does not lead to clinically relevant changes in desloratadine pharmacokinetics in vivo (Henz, 2001; McClellan and Jarvis, 2001). Furthermore, the CYP3A4 and OATP1B1 inhibitor erythromycin did not significantly increase desloratadine exposure, suggesting lack of OATP1B1 contribution in desloratadine disposition (Henz, 2001).

In the clopidogrel phase of the present study, the AUCs of 3hydroxydesloratadine and its $O$-glucuronide were markedly decreased, whereas the AUC of parent desloratadine was more than doubled. The resulting reduction in 3-hydroxydesloratadine:desloratadine $\mathrm{AUC}_{0-71 \mathrm{~h}}$ ratio by clopidogrel is consistent with an average $80 \%$ inhibition of CYP2C8 activity, assuming that clopidogrel had no effect on nonCYP2C8-mediated metabolism of desloratadine $N$-glucuronide nor on hydrolysis of either of the $\mathrm{N}$-glucuronide intermediates. With respect to clopidogrel's CYP2C8 inhibition potency, this estimate is in accordance with recent findings that clopidogrel causes about 5-fold increases in exposures to repaglinide and dasabuvir, which are among the most sensitive CYP2C8 substrates identified so far (Tornio et al., 2014; Itkonen et al., 2019).

In most individuals, gemfibrozil almost abolished 3-hydroxydesloratadine and its $O$-glucuronide from plasma, while reducing the 3-hydroxydesloratadine:desloratadine $\mathrm{AUC}_{0-71 \mathrm{~h}}$ ratio to less than $2 \%$ of that during the placebo phase (Fig. 3A; Table 1). In addition, gemfibrozil increased desloratadine exposure in all subjects. Concerning the CYP2C8inhibitory strength of gemfibrozil, the deductions inferred from the current results are highly concordant with the estimates from previous studies with gemfibrozil and the CYP2C8 substrate repaglinide, which indicated that clinical doses of gemfibrozil (600 mg BID) decrease CYP2C8 activity by $>98 \%$ (Honkalammi et al., 2012).

The effects of gemfibrozil on desloratadine pharmacokinetics resembled those of clopidogrel but were significantly more prominent, which is in line with the static predictions made on the basis of the unbound plasma $C_{\max }$ of gemfibrozil and clopidogrel glucuronides, and their in vitro mechanism-based inhibition parameters reported in the literature (Fig. 3F). The AUC of desloratadine was augmented 2.8-fold (range 1.8to 4.7-fold) and 4.6-fold (range 2.3- to 7.9-fold) by clopidogrel and gemfibrozil, respectively. The increases in desloratadine AUC caused by clopidogrel and gemfibrozil correlated with each other (Fig. 3C), and with the 3-hydroxydesloratadine:desloratadine $\mathrm{AUC}_{0-71 \mathrm{~h}}$ ratio in the placebo phase that probably reflects CYP2C8 activity at baseline (Fig. 3, D and E). These findings suggest that the basis of the effects of clopidogrel and gemfibrozil is a shared CYP2C8-selective mechanism and that interindividual variation in CYP2C8 enzyme activity largely explains the variability in sensitivity of desloratadine to CYP2C8 inhibition. The present and previous reports imply that clinical doses of gemfibrozil cause stronger interactions with CYP2C8 substrates than those of clopidogrel, thus revealing more sensitively whether CYP2C8 participates in the metabolism of the victim drug (Table 3). However, gemfibrozil also inhibits the activity of certain membrane transporters, most notably hepatic OATP1B1 (Neuvonen et al., 2006; Tornio et al., 2017), which in turn is not inhibited by clopidogrel to a clinically relevant extent (Itkonen et al., 2015; Kim et al., 2016). Therefore, interpreting the DDI mechanisms can be challenging when gemfibrozil $600 \mathrm{mg}$ BID is used as a model CYP2C8 inhibitor, if the victim drug is also a substrate of OATP1B1, as repaglinide and cerivastatin are (Backman et al., 2002, 2016; Niemi et al., 2003; Shitara et al., 2003; Niemi et al., 2005; Ogilvie et al., 2006; Tornio et al., 2017). In such cases, clopidogrel could be considered as an alternative model inhibitor.

Our current results imply that the metabolism of desloratadine to its 3-hydroxy metabolite is highly dependent on CYP2C8 activity in humans in vivo. Although gemfibrozil and clopidogrel increased the AUC of desloratadine less than they had increased the AUCs of repaglinide and dasabuvir (Table 3), the 3-hydroxydesloratadine:desloratadine ratio seemed to be highly sensitive to CYP2C8 inhibition. These observations corroborate the previous in vitro findings of Kazmi et al. (2015a) and suggest the possibility of using desloratadine as a CYP2C8 probe substrate. However, an important caveat is that the formation of 3-hydroxydesloratadine is also dependent on UGT2B10 activity (Kazmi et al., 2015b) and can probably be altered by inhibition and induction of UGT2B10. Of note, neither clopidogrel nor gemfibrozil is 
A

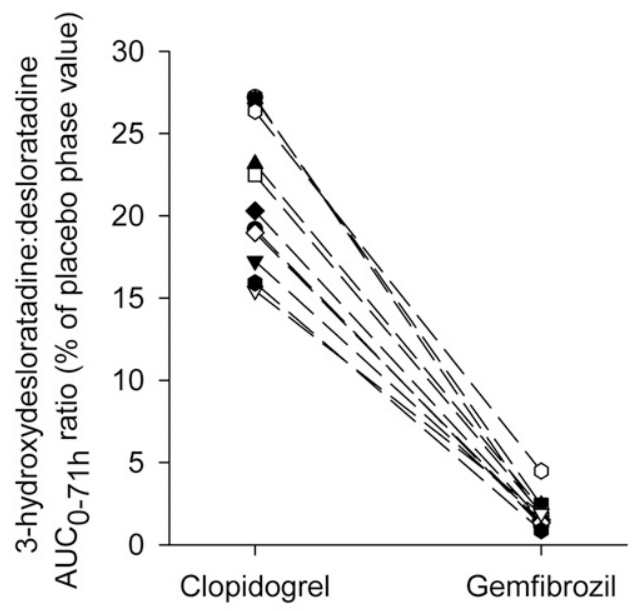

B

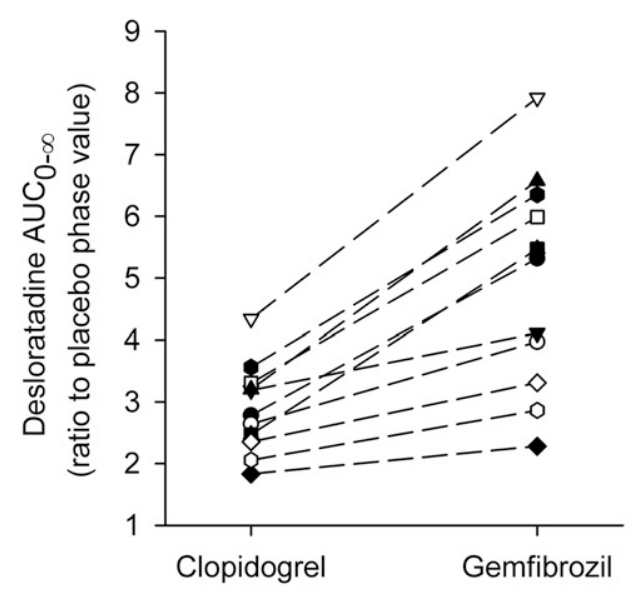

C

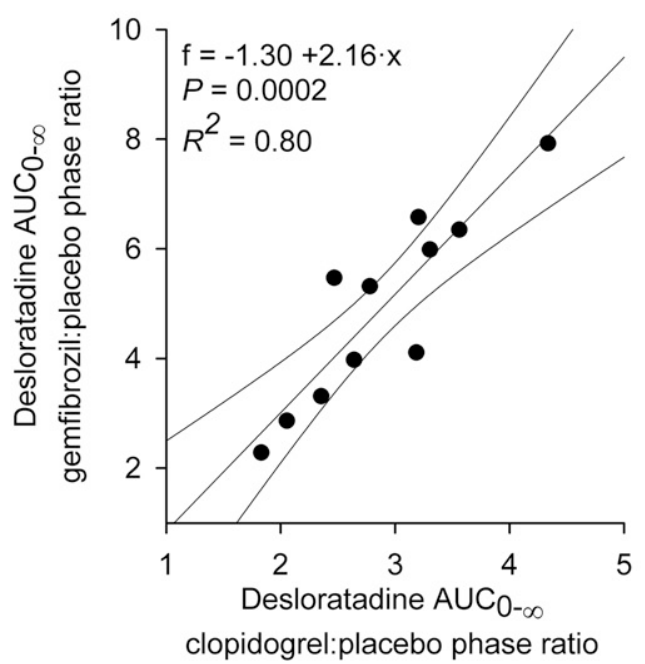

D
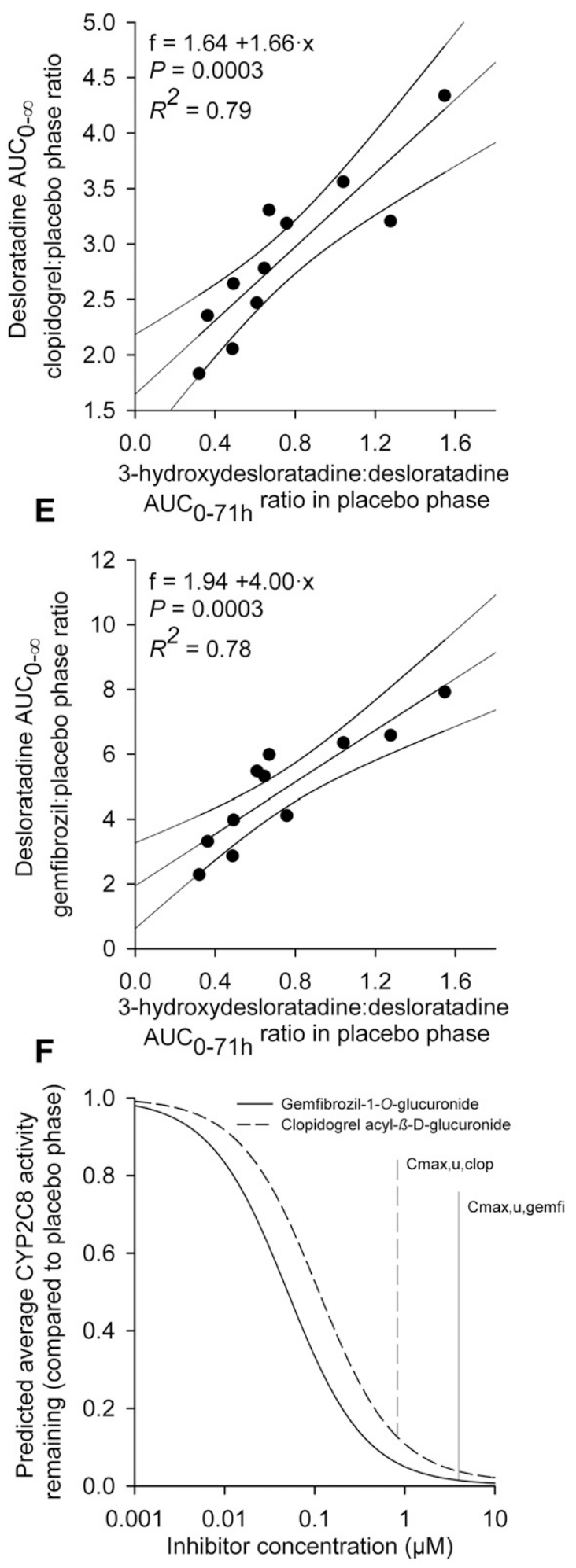

Fig. 3. The individual change in 3-hydroxydesloratadine:desloratadine area under the plasma concentration time curve ( $\left.\mathrm{AUC} \mathrm{C}_{0-71 \mathrm{~h}}\right)$ ratio $(\mathrm{A})$ and desloratadine $\mathrm{AUC} \mathrm{C}_{0-\infty}(\mathrm{B})$ in the clopidogrel and gemfibrozil phase in comparison with placebo phase value. The correlation of desloratadine $\mathrm{AUC}_{0-\infty}$ ratio between gemfibrozil to control and clopidogrel to control (C), and the correlation of 3-hydroxydesloratadine:desloratadine $\mathrm{AUC}_{0-71 \mathrm{~h}}$ ratio in the placebo phase with desloratadine $\mathrm{AUC}_{0-\infty}$ clopidogrel to control ratio (D), and desloratadine $\mathrm{AUC}_{0-\infty}$ gemfibrozil to control ratio (E), where the lines depict the linear regression with $95 \%$ CI. Predicted CYP2C8 inhibitory effect of gemfibrozil and clopidogrel using a static prediction equation whose basis was in vitro mechanism-based inhibition parameters of their glucuronide metabolites reported in the literature and their concentrations at the enzyme site (F). See Materials and Methods for details of the prediction equation. $C_{\text {max,u,clop, }}$, unbound peak plasma concentration of clopidogrel acyl- $\beta$-D-glucuronide after $300 \mathrm{mg}$ clopidogrel in the current study $(0.83 \mu \mathrm{M}$ with an estimated fraction unbound of $10 \%) ; C_{\text {max,u,gemfi }}$, unbound peak plasma concentration of gemfibrozil 1-O-glucuronide after $600 \mathrm{mg}$ gemfibrozil in the current study $(3.9 \mu \mathrm{M}$ with an estimated fraction unbound of $11.5 \%)$. 
TABLE 3

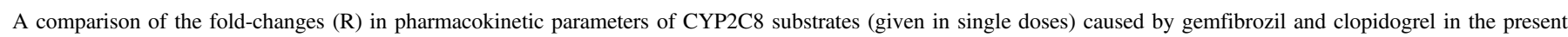
study and previous publications

Data are either arithmetic or geometric mean ratios with $90 \%$ or $95 \%$ confidence intervals (CI), or ranges.

\begin{tabular}{|c|c|c|c|c|c|c|}
\hline \multirow{2}{*}{$\begin{array}{l}\text { Victim Drug } \\
\text { and Its Dose }\end{array}$} & \multicolumn{3}{|c|}{$\begin{array}{c}\text { Clopidogrel } 300 \mathrm{mg} \text { followed by } 75 \mathrm{mg} \text { QD Ratio (R) to Placebo (90\% or } 95 \% \mathrm{CI} \text {, or } \\
\text { range) }\end{array}$} & \multicolumn{3}{|c|}{ Gemfibrozil 600 mg BID Ratio (R) to Placebo ( $90 \%$ or $95 \%$ CI, or Range) } \\
\hline & $\mathrm{AUC}_{0-\infty} \mathrm{R}$ & $C_{\max } \mathrm{R}$ & Reference & $\mathrm{AUC}_{0-\infty} \mathrm{R}$ & $C_{\max } \mathrm{R}$ & Reference \\
\hline \multicolumn{7}{|l|}{ Dasabuvir } \\
\hline $250 \mathrm{mg}$ & $4.7(90 \% \mathrm{CI}=3.2-6.7)$ & $1.6(90 \% \mathrm{CI}=1.0-2.6)$ & $\begin{array}{l}\text { Itkonen et al. } \\
\text { (2019) }\end{array}$ & $11.3(90 \% \mathrm{CI}=9.1-14)$ & $2.0(90 \% \mathrm{CI}=1.7-2.4)$ & Menon et al. (2015) \\
\hline $\begin{array}{l}\text { Desloratadine } \\
5 \mathrm{mg} \\
\text { Montelukast }\end{array}$ & $2.8(90 \% \mathrm{CI}=2.3-3.4)$ & $1.7(90 \% \mathrm{CI}=1.3-2.0)$ & Present study & $4.6(90 \% \mathrm{CI}=3.5-6.2)$ & $1.7(90 \% \mathrm{CI}=1.4-2.2)$ & Present study \\
\hline $10 \mathrm{mg}$ & $2.0(90 \% \mathrm{CI}=1.7-2.3)$ & $1.0(90 \% \mathrm{CI}=0.8-1.2)$ & $\begin{array}{l}\text { Itkonen et al. } \\
\text { (2018) }\end{array}$ & $4.4(95 \% \mathrm{CI}=3.8-5.0)$ & $1.5(95 \% \mathrm{CI}=1.3-1.8)$ & Karonen et al. (2010) \\
\hline \multicolumn{7}{|l|}{ Pioglitazone } \\
\hline $\begin{array}{l}1 \mathrm{mg} \\
15 \mathrm{mg}\end{array}$ & $\begin{array}{l}2.0(95 \% \text { CI }=1.6-2.5)^{a} \\
2.1(90 \% \mathrm{CI}=1.8-2.6)\end{array}$ & $\begin{array}{c}\text { Not reported } \\
1.0(90 \% \mathrm{CI}=0.8-1.4)\end{array}$ & $\begin{array}{l}\text { Kim et al. (2016) } \\
\text { Itkonen et al. } \\
\quad(2016)\end{array}$ & $3.2($ Range $=2.3-6.5)$ & 1.1 (Range $=0.5-2.6)$ & Jaakkola et al. (2005) \\
\hline $30 \mathrm{mg}$ & & & & $3.4($ Range $=2.3-6.2)$ & Not reported & Deng et al.(2005) \\
\hline $\begin{array}{l}\text { Repaglinide } \\
0.1 \mathrm{mg}\end{array}$ & $3.1(95 \% \mathrm{CI}=2.1-4.1)^{b}$ & Not reported & Kim et al. (2016) & & & \\
\hline \multirow[t]{4}{*}{$0.25 \mathrm{mg}$} & $5.1(90 \% \mathrm{CI}=3.9-6.6)$ & $2.5(90 \% \mathrm{CI}=1.8-3.5)$ & $\begin{array}{l}\text { Tornio et al. } \\
\quad(2014)\end{array}$ & $8.1($ Range $=5.5-15)$ & $2.4($ Range $=1.7-6.1)$ & Niemi et al. (2003) \\
\hline & $3.9(90 \% \mathrm{CI}=2.9-5.3)^{c}$ & $2.0(90 \% \mathrm{CI}=1.3-3.1)^{c}$ & $\begin{array}{l}\text { Tornio et al. } \\
\text { (2014) }\end{array}$ & $7.0($ Range $=2.9-14)$ & $2.2($ Range $=1.4-2.9)$ & Tornio et al. (2008) \\
\hline & & & & $7.6($ Range $=4.2-12)$ & $2.7($ Range $=1.5-3.7)$ & Backman et al. (2009) \\
\hline & & & & $7.0(90 \% \mathrm{CI}=6.0-8.1)$ & $2.0(90 \% \mathrm{CI}=1.6-2.5)$ & $\begin{array}{l}\text { Honkalammi et al. } \\
\text { (2012) }\end{array}$ \\
\hline
\end{tabular}

$\mathrm{AUC}_{0-8 \mathrm{~h}}$, area under the plasma concentration -time curve from 0 to 8 hours; $\mathrm{AUC}_{0-24 \mathrm{~h}}$, area under the plasma concentration-time curve from 0 to 24 hours; $\mathrm{AUC} \mathrm{C}_{0-\infty}$, area under the plasma concentration-time curve from time 0 to infinity.

${ }^{a} \mathrm{AUC}_{0-24 \mathrm{~h}}$ ratio.

${ }^{b} \mathrm{AUC}_{0-8}$ h ratio.

${ }^{c}$ Effect on day 3 of treatment with clopidogrel $300 \mathrm{mg}$ on day 1 followed by $75 \mathrm{mg}$ QD.

known to inhibit UGT2B10. Moreover, in some individuals, the $t_{1 / 2}$ and drug exposure of desloratadine are very high, resulting in a "poor metabolizer" phenotype, which has a population frequency of $17 \%$ in African-Americans and $8 \%$ in Native American but is less common in Caucasians and Hispanics, with a frequency of about $2 \%$ (Molimard et al., 2004; Prenner et al., 2006; Ramanathan et al., 2007). The "poor metabolizer" phenotype and almost complete CYP2C8 inactivation by gemfibrozil result in surprisingly similar exposures to desloratadine and its 3-hydroxy metabolite (Prenner et al., 2006). However, the most probable explanation for this phenotype is that common UGT2B10 variants prevent the expression of functional UGT2B10 (Berg et al., 2010a, 2010b; Chen et al., 2010; Murphy et al., 2014; Fowler et al., 2015). Another possibility for this phenomenon is variability in $C Y P 2 C 8$, even though nonfunctional alleles in $C Y P 2 C 8$ are rare in all major populations (Zhou et al., 2017). In any case, individuals with desloratadine "poor metabolizer" phenotype are probably less sensitive to changes in desloratadine pharmacokinetics by CYP2C8 inhibitors. Consequently, desloratadine might be suboptimal as a CYP2C8 probe substrate in, for example, African-Americans. From another perspective, the good tolerability of desloratadine and its lack of P450 inhibition could support its usefulness as a CYP2C8 probe substrate (Barecki et al., 2001; Henz, 2001).

As 3-hydroxydesloratadine possesses $\mathrm{H} 1$ receptor antagonistic properties (Murdoch et al., 2003), evaluation of the clinical significance of the effects of gemfibrozil and clopidogrel on desloratadine pharmacokinetics requires consideration of the changes in the concentrations of both desloratadine and this metabolite. It can be estimated that clopidogrel roughly doubled and gemfibrozil roughly tripled the sum exposure to desloratadine and 3-hydroxydesloratadine, which should have no hazardous consequences owing to the large therapeutic index of desloratadine (Prenner et al., 2006).
As the most probable explanation for the effects of the CYP2C8 inhibitors gemfibrozil and clopidogrel on the pharmacokinetics of desloratadine is inhibition of CYP2C8-mediated 3-hydroxylation of a glucuronide metabolite of desloratadine, our results provide clinical evidence supporting the findings of several in vitro studies that CYP2C8 has the ability to oxidize glucuronide metabolites in humans (Backman et al., 2016). On the basis of X-ray crystallographic studies, the large CYP2C8 active site cavity is capable of binding substrates diverse in structure (Schoch et al., 2008). As demonstrated in molecular docking simulations, there is a hydrophilic region in the active site that can accommodate the glucuronide moiety of certain metabolites, including clopidogrel acyl- $\beta$-D-glucuronide and gemfibrozil 1- $O$-glucuronide (Baer et al., 2009; Tornio et al., 2014; Backman et al., 2016), in contrast to most other P450 enzymes. Accordingly, molecular modeling combined with in vitro experiments provide useful means to predict CYP2C8-involved DDI potential of drugs and their metabolites.

In conclusion, our clinical study revealed two DDIs with interesting characteristics and implications. First, in the clopidogrel-desloratadine and gemfibrozil-desloratadine interactions, both the perpetrator and victim compounds are glucuronide metabolites, highlighting the need to consider the properties of xenobiotic glucuronides with respect to evaluation of the risk of pharmacokinetic DDIs. Second, despite its complex metabolism, desloratadine could serve as a safe CYP2C8 probe substrate in clinical DDI studies owing to the CYP2C8-dependent 3-hydroxydesloratadine formation. It could be especially useful if the perpetrator also inhibits CYP3A4 or OATP1B1, because it differs from other recommended CYP2C8 probe substrates that are also dependent on CYP3A4 and OATP1B1. However, the suggested sequential metabolism and obligatory role of UGT2B10 prior to CYP2C8-mediated oxidation of desloratadine (Kazmi et al., 2015a) may complicate its DDI interpretation. Therefore, the applicability of desloratadine in populations with a high prevalence 
of desloratadine "poor metabolizer" phenotype requires further studies. Last, our study confirms that gemfibrozil is a stronger CYP2C8 inhibitor than clopidogrel, but they both can be used as model CYP2C8 inhibitors, as long as their DDI profile is taken into account in the study design and interpretation.

\section{Acknowledgments}

We thank Eija Mäkinen-Pulli and Lisbet Partanen for the skillful technical assistance.

\section{Authorship Contributions}

Participated in research design: Itkonen, Tornio, M. Neuvonen, P. J. Neuvonen, Niemi, Backman.

Conducted experiments: Itkonen, Tornio, M. Neuvonen, P. J. Neuvonen, Niemi, Backman.

Performed data analysis: Itkonen, Tornio, M. Neuvonen, P. J. Neuvonen, Niemi, Backman.

Wrote or contributed to the writing of the manuscript: Itkonen, Tornio, M. Neuvonen, P. J. Neuvonen, Niemi, Backman.

\section{References}

Albrecht W, Unger A, Nussler AK, and Laufer S (2008) In vitro metabolism of 2-[6-(4-chlorophenyl)2,2-dimethyl-7-phenyl-2,3-dihydro-1H-pyrrolizin-5-yl] acetic acid (licofelone, ML3000), an inhibitor of cyclooxygenase-1 and -2 and 5-lipoxygenase. Drug Metab Dispos 36:894-903.

Backman JT, Filppula AM, Niemi M, and Neuvonen PJ (2016) Role of cytochrome P450 2C8 in drug metabolism and interactions. Pharmacol Rev 68:168-241.

Backman JT, Honkalammi J, Neuvonen M, Kurkinen KJ, Tornio A, Niemi M, and Neuvonen PJ (2009) CYP2C8 activity recovers within 96 hours after gemfibrozil dosing: estimation of CYP2C8 half-life using repaglinide as an in vivo probe. Drug Metab Dispos 37:2359-2366.

Backman JT, Kyrklund C, Neuvonen M, and Neuvonen PJ (2002) Gemfibrozil greatly increases plasma concentrations of cerivastatin. Clin Pharmacol Ther 72:685-691.

Baer BR, DeLisle RK, and Allen A (2009) Benzylic oxidation of gemfibrozil-1-O-beta-glucuronide by P450 2C8 leads to heme alkylation and irreversible inhibition. Chem Res Toxicol 22:1298-1309.

Barecki ME, Casciano CN, Johnson WW, and Clement RP (2001) In vitro characterization of the inhibition profile of loratadine, desloratadine, and 3-OH-desloratadine for five human cytochrome P-450 enzymes. Drug Metab Dispos 29:1173-1175.

Berg JZ, Mason J, Boettcher AJ, Hatsukami DK, and Murphy SE (2010a) Nicotine metabolism in African Americans and European Americans: variation in glucuronidation by ethnicity and UGT2B10 haplotype. J Pharmacol Exp Ther 332:202-209.

Berg JZ, von Weymarn LB, Thompson EA, Wickham KM, Weisensel NA, Hatsukami DK, and Murphy SE (2010b) UGT2B10 genotype influences nicotine glucuronidation, oxidation, and consumption. Cancer Epidemiol Biomarkers Prev 19:1423-1431.

Chen G, Giambrone NE Jr, Dluzen DF, Muscat JE, Berg A, Gallagher CJ, and Lazarus P (2010) Glucuronidation genotypes and nicotine metabolic phenotypes: importance of functional UGT2B 10 and UGT2B 17 polymorphisms. Cancer Res 70:7543-7552.

Delaforge M, Pruvost A, Perrin L, and André F (2005) Cytochrome P450-mediated oxidation of glucuronide derivatives: example of estradiol-17 $\beta$-glucuronide oxidation to 2-hydroxy-estradiol17ß-glucuronide by CYP 2C8. Drug Metab Dispos 33:466-473.

Deng LJ, Wang F, and Li HD (2005) Effect of gemfibrozil on the pharmacokinetics of pioglitazone. Eur J Clin Pharmacol 61:831-836.

Fowler S, Kletzl H, Finel M, Manevski N, Schmid P, Tuerck D, Norcross RD, Hoener MC, Spleiss O, and Iglesias VA (2015) A UGT2B10 splicing polymorphism common in african populations may greatly increase drug exposure. J Pharmacol Exp Ther 352:358-367.

Ghosal A, Yuan Y, Hapangama N, Su ADI, Alvarez N, Chowdhury SK, Alton KB, Patrick JE, and Zbaida S (2004) Identification of human UDP-glucuronosyltransferase enzyme(s) responsible for the glucuronidation of 3-hydroxydesloratadine. Biopharm Drug Dispos 25:243-252.

Henz BM (2001) The pharmacologic profile of desloratadine: a review. Allergy 56 (Suppl 65): $7-13$

Holmberg MT, Tornio A, Neuvonen M, Neuvonen PJ, Backman JT, and Niemi M (2014) Grapefruit juice inhibits the metabolic activation of clopidogrel. Clin Pharmacol Ther 95:307-313.

Honkalammi J, Niemi M, Neuvonen PJ, and Backman JT (2012) Gemfibrozil is a strong inactivator of CYP2C8 in very small multiple doses. Clin Pharmacol Ther 91:846-855.

Itkonen MK, Tornio A, Filppula AM, Neuvonen M, Neuvonen PJ, Niemi M, and Backman JT (2018) Clopidogrel but not prasugrel significantly inhibits the CYP2C8-mediated metabolism of montelukast in humans. Clin Pharmacol Ther 104:495-504.

Itkonen MK, Tornio A, Lapatto-Reiniluoto O, Neuvonen M, Neuvonen PJ, Niemi M, and Backman JT (2019) Clopidogrel increases dasabuvir exposure with or without ritonavir, and ritonavir inhibits the bioactivation of clopidogrel. Clin Pharmacol Ther 105:219-228.

Itkonen MK, Tornio A, Neuvonen M, Neuvonen PJ, Niemi M, and Backman JT (2015) Clopidogrel has no clinically meaningful effect on the pharmacokinetics of the organic anion transporting polypeptide 1B1 and cytochrome P450 3A4 substrate simvastatin. Drug Metab Dispos 43: $1655-1660$.

Itkonen MK, Tornio A, Neuvonen M, Neuvonen PJ, Niemi M, and Backman JT (2016) Clopidogrel markedly increases plasma concentrations of CYP2C8 substrate pioglitazone. Drug Metab Dispos 44:1364-1371.
Jaakkola T, Backman JT, Neuvonen M, and Neuvonen PJ (2005) Effects of gemfibrozil, itraconazole, and their combination on the pharmacokinetics of pioglitazone. Clin Pharmacol Ther 77:404-414.

Karonen T, Filppula A, Laitila J, Niemi M, Neuvonen PJ, and Backman JT (2010) Gemfibrozil markedly increases the plasma concentrations of montelukast: a previously unrecognized role for CYP2C8 in the metabolism of montelukast. Clin Pharmacol Ther 88:223-230.

Karonen T, Neuvonen PJ, and Backman JT (2012) CYP2C8 but not CYP3A4 is important in the pharmacokinetics of montelukast. Br J Clin Pharmacol 73:257-267.

Kazmi F, Barbara JE, Yerino P, and Parkinson A (2015a) A long-standing mystery solved: the formation of 3-hydroxydesloratadine is catalyzed by $\mathrm{CYP} 2 \mathrm{C} 8$ but prior glucuronidation of desloratadine by UDP-glucuronosyltransferase $2 \mathrm{~B} 10$ is an obligatory requirement. Drug Metab Dispos 43:523-533.

Kazmi F, Yerino P, Barbara JE, and Parkinson A (2015b) Further characterization of the metabolism of desloratadine and its cytochrome P450 and UDP-glucuronosyltransferase inhibition potential: identification of desloratadine as a relatively selective UGT2B10 inhibitor. Drug Metab Dispos 43:1294-1302.

Kim SJ, Yoshikado T, Ieiri I, Maeda K, Kimura M, Irie S, Kusuhara H, and Sugiyama Y (2016) Clarification of the mechanism of clopidogrel-mediated drug-drug interaction in a clinical cassette small-dose study and its prediction based on in vitro information. Drug Metab Dispos 44:1622-1632.

Kumar S, Samuel K, Subramanian R, Braun MP, Stearns RA, Chiu S-HL, Evans DC, and Baillie TA (2002) Extrapolation of diclofenac clearance from in vitro microsomal metabolism data: role of acyl glucuronidation and sequential oxidative metabolism of the acyl glucuronide. J Pharmacol Exp Ther 303:969-978.

McClellan K and Jarvis B (2001) Desloratadine. Drugs 61:789-796, discussion 797.

Menon RM, Badri PS, Wang T, Polepally AR, Zha J, Khatri A, Wang H, Hu B, Coakley EP, Podsadecki TJ, et al. (2015) Drug-drug interaction profile of the all-oral anti-hepatitis C virus regimen of paritaprevir/ritonavir, ombitasvir, and dasabuvir. J Hepatol 63:20-29.

Molimard M, Diquet B, and Benedetti MS (2004) Comparison of pharmacokinetics and metabolism of desloratadine, fexofenadine, levocetirizine and mizolastine in humans. Fundam Clin Pharmacol 18:399-411.

Murdoch D, Goa KL, and Keam SJ (2003) Desloratadine: an update of its efficacy in the management of allergic disorders. Drugs 63:2051-2077.

Murphy SE, Park SS, Thompson EF, Wilkens LR, Patel Y, Stram DO, and Le Marchand L (2014) Nicotine $\mathrm{N}$-glucuronidation relative to N-oxidation and C-oxidation and UGT2B10 genotype in five ethnic/racial groups. Carcinogenesis 35:2526-2533.

Neuvonen PJ, Niemi M, and Backman JT (2006) Drug interactions with lipid-lowering drugs: mechanisms and clinical relevance. Clin Pharmacol Ther 80:565-581.

Niemi M, Backman JT, Kajosaari LI, Leathart JB, Neuvonen M, Daly AK, Eichelbaum M, Kivistë KT, and Neuvonen PJ (2005) Polymorphic organic anion transporting polypeptide 1B1 is a major determinant of repaglinide pharmacokinetics. Clin Pharmacol Ther 77:468-478.

Niemi M, Backman JT, Neuvonen M, and Neuvonen PJ (2003) Effects of gemfibrozil, itraconazole, and their combination on the pharmacokinetics and pharmacodynamics of repaglinide: potentially hazardous interaction between gemfibrozil and repaglinide. Diabetologia 46:347-351

Ogilvie BW, Zhang D, Li W, Rodrigues AD, Gipson AE, Holsapple J, Toren P, and Parkinson A (2006) Glucuronidation converts gemfibrozil to a potent, metabolism-dependent inhibitor of CYP2C8: implications for drug-drug interactions. Drug Metab Dispos 34:191-197.

Prenner B, Kim K, Gupta S, Khalilieh S, Kantesaria B, Manitpisitkul P, Lorber R, Wang Z, and Lutsky B (2006) Adult and paediatric poor metabolisers of desloratadine: an assessment of pharmacokinetics and safety. Expert Opin Drug Saf 5:211-223.

Ramanathan R, Reyderman L, Su AD, Alvarez N, Chowdhury SK, Alton KB, Wirth MA, Clement RP, Statkevich P, and Patrick JE (2007) Disposition of desloratadine in healthy volunteers. Xenobiotica 37:770-787.

Regan SL, Maggs JL, Hammond TG, Lambert C, Williams DP, and Park BK (2010) Acyl glucuronides: the good, the bad and the ugly. Biopharm Drug Dispos 31:367-395.

Schoch GA, Yano JK, Sansen S, Dansette PM, Stout CD, and Johnson EF (2008) Determinants of cytochrome P450 2C8 substrate binding: structures of complexes with montelukast, troglitazone, felodipine, and 9-cis-retinoic acid. J Biol Chem 283:17227-17237.

Shitara Y, Itoh T, Sato H, Li AP, and Sugiyama Y (2003) Inhibition of transporter-mediated hepatic uptake as a mechanism for drug-drug interaction between cerivastatin and cyclosporin $\mathrm{A}$. J Pharmacol Exp Ther 304:610-616.

Tornio A, Filppula AM, Kailari O, Neuvonen M, Nyrönen TH, Tapaninen T, Neuvonen PJ, Niemi M, and Backman JT (2014) Glucuronidation converts clopidogrel to a strong timedependent inhibitor of CYP2C8: a phase II metabolite as a perpetrator of drug-drug interactions. Clin Pharmacol Ther 96:498-507.

Tornio A, Niemi M, Neuvonen PJ, and Backman JT (2012) Drug interactions with oral antidiabetic agents: pharmacokinetic mechanisms and clinical implications. Trends Pharmacol Sci 33:312-322.

Tornio A, Neuvonen PJ, Niemi M, and Backman JT (2017) Role of gemfibrozil as an inhibitor of CYP2C8 and membrane transporters. Expert Opin Drug Metab Toxicol 13:83-95.

Tornio A, Niemi M, Neuvonen M, Laitila J, Kalliokoski A, Neuvonen PJ, and Backman JT (2008) The effect of gemfibrozil on repaglinide pharmacokinetics persists for at least $12 \mathrm{~h}$ after the dose: evidence for mechanism-based inhibition of CYP2C8 in vivo. Clin Pharmaco Ther 84:403-411

Zhou Y, Ingelman-Sundberg M, and Lauschke VM (2017) Worldwide distribution of cytochrome P450 alleles: a meta-analysis of population-scale sequencing projects. Clin Pharmacol Ther 102: 688-700.

Address correspondence to: Dr. Aleksi Tornio, Department of Clinical Pharmacology, University of Helsinki, PO Box 20, Fl-00014 University of Helsinki, Finland. E-mail: aleksi.tornio@helsinki.fi 